\title{
Z6

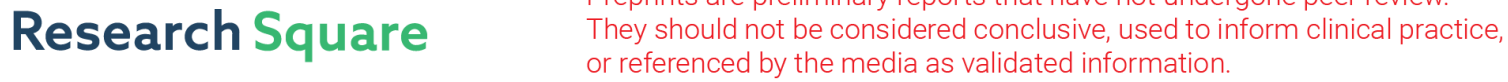 \\ Extracellular Vesicles From Steatotic Hepatocytes Provoke Pro-Fibrotic Responses in Stellate Cells.
}

\section{Teresa Koenen}

RWTH Aachen University Medical Faculty: Rheinisch-Westfalische Technische Hochschule Aachen Medizinische Fakultat

\section{Tim Caspers}

RWTH Aachen University Medical Faculty: Rheinisch-Westfalische Technische Hochschule Aachen Medizinische Fakultat

\section{Alexandra C.A. Heinzmann}

Universiteit Maastricht CARIM School for Cardiovascular Diseases: Universiteit Maastricht

Cardiovascular Research Institute Maastricht

\section{Petra Fischer}

RWTH Aachen University Medical Faculty: Rheinisch-Westfalische Technische Hochschule Aachen Medizinische Fakultat

\section{Daniel Heinrichs}

RWTH Aachen University Medical Faculty: Rheinisch-Westfalische Technische Hochschule Aachen Medizinische Fakultat

\section{Elisa F. Brandt}

RWTH Aachen University Medical Faculty: Rheinisch-Westfalische Technische Hochschule Aachen Medizinische Fakultat

\section{Theresa Wirtz}

RWTH Aachen University Medical Faculty: Rheinisch-Westfalische Technische Hochschule Aachen Medizinische Fakultat

\section{Christian Trautwein}

RWTH Aachen University Medical Faculty: Rheinisch-Westfalische Technische Hochschule Aachen Medizinische Fakultat

\section{Rory Koenen ( $\nabla$ r.koenen@maastrichtuniversity.nl )}

Universiteit Maastricht Cardiovascular Research Institute Maastricht https://orcid.org/0000-00029955-9730

\section{Marie Luise Berres}

RWTH Aachen University Medical Faculty: Rheinisch-Westfalische Technische Hochschule Aachen Medizinische Fakultat 
Keywords: stellate cell, liver fibrosis, extracellular vesicles, non-alcoholic fatty liver disease

Posted Date: September 22nd, 2020

DOI: https://doi.org/10.21203/rs.3.rs-79345/v1

License: (c) (1) This work is licensed under a Creative Commons Attribution 4.0 International License. Read Full License 


\section{Abstract}

\section{Background and aims}

High caloric dietary intake is associated with hepatic steatosis and chronic hepatocyte damage leading ultimately to liver fibrosis and cirrhosis with organ failure. Although the pathophysiologic process orchestrating liver fibrosis is not completely clarified, pivotal steps are the activation and transdifferentiation of hepatic stellate cells. In this study, we aim to assess the direct interplay between hepatocytes and hepatic stellate cells under normal and steatotic conditions and hypothesize that extracellular vesicles (EV) isolated from hepatocytes can directly manipulate the phenotype of stellate cells.

\section{Methods}

By high speed centrifugation, EV were isolated from conditioned media of the hepatocellular carcinoma cell line HepG2, under baseline conditions (C-EV) or after induction of steatosis by linoleic and oleic acid for 24 hours (FA-EV). Migration of the stellate cell line TWNT4 towards respective EV as well as sera of NASH patients was investigated using Boyden chambers. TWNT4 phenotype alterations after incubation with EV was determined by qPCR, western blotting and immunofluorescence staining.

\section{Results}

HepG2 cells released more EV after treatment with fatty acids. Chemotactic migration of TWNT4 cells was increased specifically towards FA-EV. Prolonged incubation of TWNT4 cells with FA-EV induce expression of proliferation markers and a myofibroblast-like phenotype. Whereas the expression of the collagen type $1 \otimes 1$ gene did not change after FA-EV-treatment, expression of the myofibroblast markers e.g. 囚-smooth muscle cell actin and TIMP1 were significantly increased.

\section{Conclusion}

We concluded that EV from steatotic HepG2 cells can influence the behavior and phenotype of TWNT4 cells as well as the expression of remodeling markers and guides directed migration. These findings imply EV as operational, intercellular communicators in the pathophysiology of steatosis associated liver fibrosis.

\section{Introduction}

Non-alcoholic fatty liver hepatitis (NASH) is the leading cause of liver disease in the western world [1]. Obesity, dyslipidemia and type 2 diabetes mellitus are the main pathogenic triggers [2]. NASH is clinically defined by atypical aspects during imaging and an increase in transaminases and cholestasis parameters. It leads to liver fibrosis and with long-term progression to cirrhosis [3, 4], which is associated with numerous potentially lethal complications such as gastrointestinal bleeding, coagulation disorders 
The emergence and progression of NASH at the cellular level is the subject of many current research projects. Although the diverse aspects of the pathophysiology of NASH remain to be completely characterized, it becomes increasingly clear that inflammation plays a pivotal role [6]. For example, altered microbiota and gut permeability during obesity may result in low grade systemic inflammation contributing to the development of NASH [7-9]. In addition, dyslipidemia and adipocytokines from visceral adipose tissue are considered to initiate and propagate liver inflammation [3]. Subsequent drivers are fatty acid-, cytokine- and cholesterol-induced stress responses in Kupffer cells and hepatocytes, leading to the release of fibrogenic factors e.g. transforming growth factor beta (TGF-- [10], platelet-derived growth factor (PDGF) $[11,12]$ and chemokines e.g. CCL2 and CCL5. These factors consecutively promote activation and differentiation of hepatic stellate cells into myofibroblasts and the recruitment of additional inflammatory cells e.g. classical monocytes into the liver [13-17].

Hepatic stellate cells are central in the pathophysiology of liver fibrosis by responding to the fibrogenic and morphogenic signals mainly derived from infiltrated bone marrow-derived macrophages and resident Kupffer cells $[4,18]$. Transdifferentiation of stellate cells is associated with the expression of myofibroblast markers e.g. \-smooth muscle cell actin (ख-SMA), matrix metalloproteinases (MMPs), vimentin and glial fibrillary acidic protein (GFAP) and extracellular matrix components e.g. collagen types I and III $[19,20]$. Excessive extracellular matrix production along with ineffective resorption are the key processes in organ fibrosis [21].

Extracellular vesicles (EV) are small cell fragments measuring up to $1000 \mathrm{~nm}$ encased by fragments of the endosomal or surface membranes of their parent cells [22, 23]. EV are released into the immediate environment of the parent cells and may be transported through the bloodstream to distal areas of the organism. Their content is composed of proteins, lipids and nucleic acid sections of the parent cell. EV can be incorporated by target cells and may thereby influence the behavior of the recipient cell. Thus, EV can be considered as a physiologic mechanism for cell-cell communication not requiring direct spatial interaction. Previous work by us and by others has demonstrated that $\mathrm{EV}$ can alter the behavior of target cells $[24,25]$. Also, hepatocytes have been found to release increased amounts of EV after treatment with fatty acids and these EV were able to activate macrophages [26].

In the present work, the influence of EV derived from fatty HepG2 cells on hepatic stellate cells is evaluated. The hypothesis is that hepatocytes stressed by fatty acid excess can transmit signals through EVs to hepatic stellate cells, which may facilitate the transformation of resting stellate cells to active myofibroblasts and thus promote initiation and progression of the fibrogenic process during NASH.

\section{Materials And Methods}

\section{Patient samples, Reagents and cell lines}

TWNT-4, immortalized human stellate cells, kindly provided by Professor Scott Friedman, Icahn School of Medicine at Mount Sinai, NY, USA [27], and HepG2, human hepatoma cells, were cultured in filtered Loading [MathJax]/jax/output/CommonHTML/jax.js PMEM) with $2 \%$ or $10 \%$ fetal bovine serum (Pan-Biotech 
$\mathrm{GmbH}$, Aidenbach, Germany) and 1\% penicillin and streptomycin (Thermo Fisher Scientific, USA) at passages $3-8$ in $37^{\circ} \mathrm{C}$ and $5 \% \mathrm{CO}_{2}$ in a humidified incubator. For induction of a steatotic phenotype, the cells were treated with $10 \%$ linoleic-oleic-acid (Sigma-Aldrich, USA) for $24 \mathrm{~h}$.

Serum was taken from female and male patients with diagnosed NASH ( $n=5, \mathrm{~m}: \mathrm{f} 3: 2$, age 43-77 years, mean 52.6 years) and controls ( $n=5$, m:f 3:2, age 33-56 years, mean 44.8 years) by venipuncture after informed consent was obtained. The study has been approved by the University Hospital RWTH Aachen ethics board.

\section{Isolation of EV}

EV were isolated from conditioned cell culture supernatants collected up to $300 \mathrm{ml}$ as previously described [25] according to ISEV recommendations [28]. The medium was filtered through $0.8 \mu \mathrm{m}$ filters (Sartorius) by gravity flow and subsequently centrifuged at $20,000 \mathrm{~g}$ for $1 \mathrm{~h}$ at $16^{\circ} \mathrm{C}$. The pellet was resuspended in Hepes buffer pH $6.6(10 \mathrm{mM}$ Hepes, $136 \mathrm{mM} \mathrm{NaCl}, 2.7 \mathrm{mM} \mathrm{KCl}, 2 \mathrm{mM} \mathrm{MgCl} 2,5 \mathrm{mM}$ glucose and $0.1 \% \mathrm{BSA}$ ).

\section{Quantification of EV}

Concentrations and vesicle size distributions were determined by NTA (nanoparticle tracking analysis, Malvern NanoSight NS300, Malvern Technologies, Malvern, UK) equipped with a 488nm laser at 1:100 or 1:1,000 dilutions. Every sample was counted for 5 times 1 minute at $20^{\circ} \mathrm{C}$. The camera level was set at 16 and traces were analyzed using NTA 3.1.54 software with a detection threshold of 5 as described [25]. To compare the cellular release of EV between treatments, the absolute counts of EVs in the cell media samples were normalized to the cell count in the respective culture vessels.

\section{Cell migration by Boyden chamber}

Home-made filter chambers were assembled with Whatman Nuclepore ${ }^{\text {TM }}$ Track-Etched filters (Sigma Aldrich, USA), coated with gelatine prior to use. The lower chamber was filled with DMEM/2\% FBS and the chemoattractant or undiluted patient and control sera $(800 \mu \mathrm{l})$. As a positive control for the TWNT4 cells, CCL5 at $10 \mathrm{ng} / \mathrm{ml}$ was used (PeproTech, Hamburg, Germany). The upper chamber was filled with $2 \times 10^{5}$ TWNT4 cells in $250 \mu \mathrm{lDMEM} / 2 \% \mathrm{FBS}$. After $4 \mathrm{~h}$ at $37^{\circ} \mathrm{C}$ and $5 \% \mathrm{CO}_{2}$, membranes were stained using the hemacolor quick stain kit (Merck) and cells quantified under a microscope. Five view fields were counted per filter. For every probe three filters were evaluated.

\section{Qualitative and quantitative DNA analysis by RT-PCR}

For RNA isolation, peqGOLD TriFast ${ }^{\text {TM }}$ was used according the manufacturer's instructions (VWR international, Darmstadt, Germany). RNA-containing pellets were resuspended in nuclease free water and concentrations were determined using a NanoDrop spectrometer (Thermo Fisher, Darmstadt, Germany). cDNAs were generated using Maxima First Strand cDNA Synthesis Kit (Thermo Fisher, Darmstadt, Loading [MathJax]/jax/output/CommonHTML/jax.js -PCR analysis was performed using GoTaq®, qPCR 
Mastermix (Promega, Madison, WI) with primers for PLIN2, KI67, PCNA, ASMA, COL1A1, TIMP1, TGFB1, $18 \mathrm{~S}$, and MMP2. The cycler program was 2 minutes at $50^{\circ} \mathrm{C}, 10$ minutes at $95^{\circ} \mathrm{C}$, and 1 min at $60^{\circ} \mathrm{C}$ for 40 cycles using a qPCR system Applied Biosystems 7300 (Thermo Fisher, Darmstadt, Germany). DeltadeltaCT values were calculated relative to the housekeeping gene $18 \mathrm{~S}$ and results were normalized to controls.

Protein determination by bicinchoninic acid assay (BCA)

Protein concentrations were determined using the BCA method (Bio-Rad, Hercules, CA). Cells were cultured in 6-well plates and washed for 2 times with PBS, lysed in 300 $\mu$ l RIPA-buffer, incubated with reagents and absorbance was measured at 560nm in a microplate reader. Concentrations were calculated using a standard curve prepared with BSA.

\section{SDS-PAGE and Western Blot}

For protein analysis, NuPAGE 4-12 \% Bis-Tris Gel SDS-PAGE was performed in MOPS-SDS running buffer (Thermo Fisher, Darmstadt, Germany) for 60 minutes at $160 \mathrm{~V}$ and proteins were subsequently transferred to nitrocellulose (Whatman, GE Life Science) for 1 hour at 100V. The membranes were blocked using 5\% BSA and incubated with primary and peroxidase-conjugated secondary antibodies prior to detection using enhanced chemiluminescence.

\section{Cell viability}

TWNT4 cells were added at 50.000 per well in a 96-well microplate and cultured overnight under the conditions described above. Media were replaced with fresh medium containing EVs at 300 per cell and cultured for further $12 \mathrm{~h}$. Then, $25 \mathrm{ng}$ CCL5 was added and culture was continued for $24 \mathrm{~h}$. As positive control, cells were treated with $30 \% \mathrm{H}_{2} \mathrm{O}_{2}$. Cell-Titer-Blue-reagent (Promega, Fitchburg, USA) was added for $2 \mathrm{~h}$ followed by measurement of the fluorescent signal at $560 \mathrm{em} / 590 \mathrm{ex} \mathrm{nm}$.

\section{Oil-red-O and phalloidin staining}

Cells were seeded in 4-well chamber slides at 50,000 cells per well. After $24 \mathrm{~h}$, the cells were stimulated overnight with EVs (300 per cell) and CCL5 (10ng/mL).

To investigate lipid uptake, linoleic-oleic acid $(300 \mu \mathrm{M})$ was added to HepG2-cells and culture was continued for further $24 \mathrm{~h}$. Medium was removed, cells were washed with PBS, fixed with $4 \%$ formaldehyde for 5 minutes and washed again. Intracellular lipid vacuoles were stained in filtered $0.12 \%$ Oil-red-0 in $20 \%$ isopropanol for $1 \mathrm{~h}$. Cells were washed with water. After staining of nuclei for 25 seconds in Mayer's hematoxylin solution (Sigma-Aldrich), cells were washed again and covered with a cover slip treated with glycerine-gelatine. Evaluation of Oil-red-O uptake was performed by light microscopy.

To visualize the cytoskeleton in TWNT4-cells, medium was removed, and cells were washed with PBS, fivan in 10/ farmaldahudn and innchad arain with PBS prior to permeabilization by $0.1 \%$ Triton-X100 in Loading [MathJax]/jax/output/CommonHTML/jax.js 
PBS for 15 minutes. After washing with PBS, cells were blocked in 1\% BSA-PBS for $1 \mathrm{~h}$. Anti-collagen antibody (Thermo Fisher Scientific) was given to the cells for one hour. Fluorescein-conjugated phalloidin (1U in 1\% BSA/PBS) was added for 30 minutes. The cells were washed with PBS and nuclei were colored by DAPI. Evaluation of cytoskeletal staining was performed by fluorescence microscopy at $490 / 530 \mathrm{~nm}$. Corrected total cell fluorescence (CTCF) was calculated using Image J 1.5 as described in [30].

\section{Cell proliferation measurement}

The 5-bromo-2'-deoxyuridine (BrdU) assay (Invitrogen) was used for quantification of proliferating cells according to the manufacturer's instructions.

Flow cytometry analysis of CCR5 surface expression

TWNT-4 were seeded at 100,000 cells per well in a 96-well plate and were allowed to rest overnight. Cells were treated with $10 \mathrm{ng} / \mathrm{ml}$ CCL 5 or $300 \mathrm{EV} /$ cell for $24 \mathrm{~h}$. Cells were detached, filtered using a cell strainer, washed in PBS and stained in the dark with rat anti-human/mouse CCR5 FITC-conjugated antibody (clone HEK/1/85a from Thermo Fisher) for $1 \mathrm{~h}$ at $4^{\circ} \mathrm{C}$. The cells were subsequently stained with Fixable Viability Dye eFluor450 (eBioscience, cat. 65-0863-18) for a further 30min. A negative control only contained viability dye. Cells were gated according to FSC and SSC parameter and live cells using a FACSCanto II (Becton Dickinson). Data were processed and analyzed using FlowJo 7.6 software (LC sciences).

\section{Statistics}

All authors had access to the study data and have reviewed and approved the final manuscript. All data generated or analysed during this study are included in this published article. Experiments were performed at least 3 independent times. Experimental data were represented as mean \pm SEM. Statistical analysis of the data were performed by two-tailed t-test or ANOVA with Bonferroni post-hoc test as indicated in the figure legends. A P-value below 0.05 was considered significant. Statistical analysis was performed with Graphpad Prism 8 software (San Diego, CA, US)

\section{Results}

HepG2 cells release increased amounts of EV under steatogenic conditions.

The hepatocellular carcinoma cell line HepG2 was treated without or with a mixture of linoleic and oleic acid (fatty acids, FA) and the release of EV by HepG2 cells under baseline conditions (C-EV) and after treatment with FA (FA-EV) was assessed in conditioned culture media collected over 24 hours.

Characterization of the EV derived from those HepG2 cells by NTA showed that the average size of 0.17 $\mu \mathrm{m}$ was comparable between EV isolated after either treatment (Figure 1A,B). The HepG2 cells were found to constitutively release extracellular vesicles (EV) in the culture media (Figure 1C). Interestingly and in line with previous studies, the number of EV released per cell was significantly pronounced after 
$\mathrm{O}$ (Figure 1D) and increased cellular triglyceride content (Figure 1F). In addition, the expression of the lipid droplet-associated perilipin (PLIN-1) and fatty acid binding protein 1 (FABP1) were increased (Figure $1 F, G)$.

\section{EV from HepG2 modulate migration of stellate cells.}

Steatotic hepatocytes have been shown to secrete several factors, including distinct cytokines and EVs, which could be measured in the sera of individuals with fatty liver disease [26, 31]. These factors might directly impact biological features of hepatic stellate cells such as their migration to sites of release and thereby modulate the distribution of hepatic stellate cells and fibrotic response in the tissue.

In a Boyden chamber setup, TWNT-4 cells, a human hepatic stellate cell line, were allowed to migrate towards the established chemoattractant CCL5, serum from healthy individuals and those with clinically diagnosed NASH. Interestingly, the sera from healthy individuals did not induce migration of TWNT-4 cells, whereas TWNT-4 cells showed pronounced migration towards sera from NASH patients (Figure 2A). However, of course, a myriad of factors within the sera might contribute to the enhancement of hepatic stellate cells migration to a distinct extent. To specifically address the impact of HepG2-derived EV on hepatic stellate cell function, we went back to the controlled in vitro setting and assess EV associated modulation of distinct hallmarks of hepatic stellate cell biology. We started with analyzing C-EV and FAEV induced TWNT-4 migration. Stellate cells are activated by and migrate to various molecular cues. For example, the chemokine CCL5 was found to trigger migration of TWNT-4 stellate cells and to be involved in the development of experimental liver fibrosis [16]. In line with the findings in the patient sera setting, FA-EV triggered chemotactic migration of TWNT-4 cells to the same extent as CCL5, whereas C-EV did not trigger chemotaxis (Figure 2B). In this regard, further analyses were mainly focused on FA-EV. Interestingly, when the TWNT-4 were co-cultured with FA-EV prior to chemotaxis, the cells no longer migrated towards CCL5 (Figure 2C). To rule out that the impaired migration was due to the loss of expression of the CCL5 receptor CCR5 on the surface of the cells, we perform flow cytometry based analyzed of the surface expression levels of CCR5 on the TWNT-4 cells, which remained unaltered after co-culture with EV of either origin (Figure $2 \mathrm{D}, \mathrm{E}$ ).

EV from HepG2 increase the proliferation of TWNT-4 stellate cells.

Activation of hepatic stellate cells leads to mitogenic responses and increased proliferation $[3,4]$. We therefore next assessed the impact of HepG2-derived EV on hepatic stellate cells proliferation. TWNT-4 cells were stimulated with CCL5 and with FA-EV for 24 hours, and proliferation was determined by BrdU incorporation as well as by the mRNA expression of the proliferation marker Ki-67 and PCNA. Expression of Ki67 and PCNA were increased in TWNT-4 cells after treatment with FA-EV. The BrdU incorpation was also significantly enhancedFigure $3 \mathrm{~A}-\mathrm{C}$ ). The viability of the TWNT-4 cells was not reduced after treatment with CCL5 or FA-EV, although the combination of CCL5 and FA-EV led to a notable reduction of cell viability (Figure 3D). 
EV from steatotic HepG2 modulate the expression of matrix myofibroblast-and remodeling-markers in stellate cells.

Stellate cells are crucially involved in fibrotic liver remodeling and are considered as the central effectors of liver fibrosis [3, 4]. Once hepatic stellates are activated, they undergo a process of transdifferentiation and gain a myofibroblast-like phenotype associated with the synthesis and release of collagen and matrix remodeling factors such as TIMP-1. Since hepatic stellate cells are in direct proximity to hepatocytes, a possible influence of EV derived from HepG2 cells under steatotic conditions on transdifferentiation and collagen production was investigated in TWNT4 cells. After treatment of TWNT4 cells with CCL 5 and FA-EV for 24 hours, the fraction of elongated cells that have assumed a myofibroblast-like morphology has significantly increased almost 1.5-fold (Figure 4A-D). In addition, expression levels myofibroblast markers $\mathbb{B}$-SMA, GFAP and vimentin were significantly increased after treatment with FA-EV (Figure 4E-G).

In contrast, collagen production visualized by fluorescence microscopy and mRNA expression levels of the collagen type $1 \otimes 1$ gene (COL1A1) as well as TGF- $ß$ did not significantly change after FA-EV-treatment (Figure 5A-E). However, expression of the matrix remodeling markers TIMP1 and MMP2 increased significantly after incubation with FA-EV (Figure 5F-H).

\section{Discussion}

In this study, the effects of EV harvested from FA-treated HepG2 cells (FA-EV) on stellate TWNT4 cells were investigated. In accordance with previous observations, treatment of HepG2 cells with lipotoxic compounds e.g. lysophosphatidylcholine (LPC) or its precursors palmitic and oleic acid leads to an increase of EV formation [26, 31-33]. Given the important function of hepatic stellate cells in liver inflammation and the progression from steatosis to fibrosis, human TWNT4 cells were used as a model system to investigate mechanisms behind the transition of hepatic steatosis to fibrosis.

In chemotaxis experiments, TWNT4 cells showed migration solely towards sera of individuals with NASH, whereas control sera did not induce any effects. Thus, NASH sera may contain increased amounts of inflammatory factors that induce responses in target cells, e.g. hepatic stellate cells. As previous studies have identified increased amounts of cytokines [26] or EV [31] in sera from NASH patients, it was hypothesized that EV derived from steatotic HepG2 cells might induce these effects in TWNT4 cells. Interestingly, TWNT4 cells were found to migrate only towards FA-EV and CCL5 and not towards control EV from HepG2 cells. A possible explanation is that the lipotoxic effects of the FA-treatment results in an altered packaging of the EV cargo, with an enrichment of components involved in inflammation or cell proliferation. For example, Hirsova and colleagues observed an enrichment of the cell death- and inflammation-related Tumor Necrosis Factor Related Apoptosis Inducing Ligand (TRAIL) in EV isolated from LPC-treated hepatocellular carcinoma Huh7 cells [26]. In other studies, it was observed that EV from LPC-treated Huh7 cells were enriched in integrin ${ }^{1}$ [31] or CXCL10 [33]. In addition to proteins, also 
bioactive lipids e.g. ceramides might be enriched in EV released from hepatocytes after treatment with fatty acids [32].

Interestingly, although TWNT4 cells actively migrated towards a gradient of FA-EV, culture of TWNT4 with FA-EV prior to the chemotaxis experiment abolished chemotaxis towards CCL5, an established chemoattractant for these cells [16]. This was not due to alterations in the surface expression of CCR5, which was found to be equal on the cells between all treatments. It might be surprising that the FA-EV induce chemotaxis on the short term and inhibit this process on the longer term. However, once the stellate cells are at the site of inflammation, they may be kept in place by migration-inhibiting signals contained in the FA-EV. In addition to local effects of fatty acid-induced EV release, EVs from damaged hepatocytes might also attract the stellate cells over a longer distance to the focus of developing disease. It is tempting to speculate that this might be among the causes of the typical histological fibrosis image in NASH cirrhosis, which presents itself as sinusoidal fibrosis, while others, for example toxic cirrhosis like alcohol, have a periportal fibrosis pattern (Figure 6). Thus, a chemotactic effect of the EVs, as suggested by our experiments, would cause the stellate cells to migrate along the liver sinusoids. The EVs are incorporated by the stellate cells once in contact at higher concentrations, which might lead to arrest of migration and production of extracellular matrix to cause the specific image of the "chicken wire" fibrosis - collagen fibers along the sinusoids lined by steatotic hepatocytes [34].

Once hepatic stellate cells had arrived at the site of inflammation, proliferation and production of extracellular matrix are further processes finally inducing the progression to liver fibrosis. Treatment of TWNT4 cells with FA-EV led to an increase in BrdU incorporation and of proliferation markers. Cell viability was not significantly affected by FA-EV, although the combination of CCL5 and FA-EV led to a notable reduction in cell viability. Interestingly, whereas the production of collagen by FA-EV-treated TWNT4 cells did not significantly increase, the cells seemed to change phenotype to an elongated appearance typical of myofibroblasts $[19,35]$. In addition, the expression of several markers of a myofibroblast phenotype were found to be increased in TWNT4 cells after FA-EV-treatment. Thus, FA-EV have the potential to modulate the responses of recipient cells. This phenomenon has been observed by several studies and supports the concept of EV as mediators of cell-to-cell communication [23]. However, while most of the studies investigating the effects of EV derived from FA-treated hepatocytes focused on macrophages as recipients[26, 31-33, 36, 37], this study systematically characterized for the first time the functional consequences of FA-EV treatment on hepatic stellate cells.

Two recent studies implementing next generation sequencing have yielded novel mechanistic insights in the cellular mechanisms governing the development of NASH and liver fibrosis ([38] and [39], respectively). Interestingly, unsupervised clustering of single-cell sequencing data revealed the involvement of a variety of non-parenchymal cell types and their subpopulations. A surprising involvement of endothelial cells, which exist in distinct subpopulations in NASH and fibrotic livers and might control liver metabolism and populate the fibrotic niche. In addition, a special type of macrophages expressing Triggering Receptors Expressed on Myeloid cells 2 (TREM2) was identified. Although no study pment of this macrophage subset has been published so far, 
a role for EV-mediated signaling in this process can be envisioned. The study investigating cell populations in human and mouse NASH has taken effort to unravel intercellular signaling between the identified cell types[38]. Here, hepatic stellate cells were found to be an important cellular hub, both in receiving and transmitting signals from and to hepatocytes, macrophages and endothelial cells. Although a role of EV in the trafficking of these cellular signals has not been explicitly taken into account, the numerous recent studies that highlighted EV as mediators make a strong case for their integral role in intercellular signaling leading to NASH and liver fibrosis.

In this study, an EV-mediated signal transmission from FA-treated hepatocytes to hepatic stellate cells was investigated. Although other cell types are instrumental in the development of liver disease, hepatic stellate cells are central in the orchestration of the pathologic responses of non-parenchymal cells in the liver. An excessive flow of hepatocyte-derived EV to macrophages and stellate cells might facilitate the development of NASH and liver fibrosis through their potential to modulate cellular phenotype and behavior. Thus, future investigation of this process might not only lead to potentially novel options for therapeutic intervention, but also to improved diagnostic insights through analysis of plasma EV numbers and content.

\section{Declarations}

\section{Acknowledgments}

The authors thank Steffen Gräber and Willi Jahnen-Dechent for kind assistance with the nanoparticle tracking analysis.

\section{Funding information}

This work was supported by the START-Program from the Medical Faculty of the RWTH Aachen awarded to M.T.K. and by the Landsteiner Foundation for Blood Transfusion Research (LSBR Nr. 1638) awarded to R.R.K. In addition, M.T.K. was supported by the Clinician Scientist Stipendium of the Medical Faculty of the RWTH Aachen. M.L.B. is supported by the Federal Ministry of Education and Research, LiSym Consortium (FKZ 031L0041).

\section{Conflict of interest statement}

The authors confirm that there are no conflicts of interest.

\section{Author contributions}

MTK: obtained funding, analyzed data, coordinated study, wrote manuscript; TC, SG, WJD, ACAH, PF, DH, EB: performed experiments; CT: obtained funding and intellectual input; RRK: obtained funding and provided intellectual input, wrote the manuscript; MLB: obtained funding, provided intellectual input, critically edited the manuscript, coordinated study. 


\section{References}

[1] Younossi ZM, Koenig AB, Abdelatif D, Fazel Y, Henry L, Wymer M. Global epidemiology of nonalcoholic fatty liver disease-Meta-analytic assessment of prevalence, incidence, and outcomes. Hepatology 2016;64(1):73-84.

[2] Walenbergh SM, Koek GH, Bieghs V, Shiri-Sverdlov R. Non-alcoholic steatohepatitis: the role of oxidized low-density lipoproteins. J Hepatol 2013;58(4):801-10.

[3] Tsuchida T, Friedman SL. Mechanisms of hepatic stellate cell activation. Nat Rev Gastroenterol Hepatol 2017;14(7):397-411.

[4] Trautwein C, Friedman SL, Schuppan D, Pinzani M. Hepatic fibrosis: Concept to treatment. J Hepatol 2015;62(1 Suppl):S15-24.

[5] Villanueva A, Luedde T. The transition from inflammation to cancer in the liver. Clin Liver Dis (Hoboken) 2016;8(4):89-93.

[6] Cordeiro A, Costa R, Andrade N, Silva C, Canabrava N, Pena MJ, Rodrigues I, Andrade S, Ramalho A. Does adipose tissue inflammation drive the development of non-alcoholic fatty liver disease in obesity? Clin Res Hepatol Gastroenterol 2020.

[7] Henao-Mejia J, Elinav E, Jin C, Hao L, Mehal WZ, Strowig T, Thaiss CA, Kau AL, Eisenbarth SC, Jurczak MJ, Camporez JP, Shulman GI, Gordon JI, Hoffman HM, Flavell RA. Inflammasome-mediated dysbiosis regulates progression of NAFLD and obesity. Nature 2012;482(7384):179-85.

[8] Le Roy T, Llopis M, Lepage P, Bruneau A, Rabot S, Bevilacqua C, Martin P, Philippe C, Walker F, Bado A, Perlemuter G, Cassard-Doulcier AM, Gerard P. Intestinal microbiota determines development of nonalcoholic fatty liver disease in mice. Gut 2013;62(12):1787-94.

[9] Aron-Wisnewsky J, Vigliotti C, Witjes J, Le P, Holleboom AG, Verheij J, Nieuwdorp M, Clement K. Gut microbiota and human NAFLD: disentangling microbial signatures from metabolic disorders. Nat Rev Gastroenterol Hepatol 2020.

[10] Hellerbrand C, Stefanovic B, Giordano F, Burchardt ER, Brenner DA. The role of TGFbeta1 in initiating hepatic stellate cell activation in vivo. J Hepatol 1999;30(1):77-87.

[11] Apte MV, Haber PS, Darby SJ, Rodgers SC, McCaughan GW, Korsten MA, Pirola RC, Wilson JS. Pancreatic stellate cells are activated by proinflammatory cytokines: implications for pancreatic fibrogenesis. Gut 1999;44(4):534-41.

[12] Kocabayoglu P, Lade A, Lee YA, Dragomir AC, Sun X, Fiel MI, Thung S, Aloman C, Soriano P, Hoshida Y, Friedman SL. beta-PDGF receptor expressed by hepatic stellate cells regulates fibrosis in murine liver Loading [MathJax]/jax/output/CommonHTML/jax.js 5;63(1):141-7. 
[13] Heymann F, Hammerich L, Storch D, Bartneck M, Huss S, Russeler V, Gassler N, Lira SA, Luedde T, Trautwein C, Tacke F. Hepatic macrophage migration and differentiation critical for liver fibrosis is mediated by the chemokine receptor C-C motif chemokine receptor 8 in mice. Hepatology 2012;55(3):898909.

[14] Karlmark KR, Weiskirchen R, Zimmermann HW, Gassler N, Ginhoux F, Weber C, Merad M, Luedde T, Trautwein C, Tacke F. Hepatic recruitment of the inflammatory Gr1+ monocyte subset upon liver injury promotes hepatic fibrosis. Hepatology 2009;50(1):261-74.

[15] Krenkel O, Puengel T, Govaere O, Abdallah AT, Mossanen JC, Kohlhepp M, Liepelt A, Lefebvre E, Luedde T, Hellerbrand C, Weiskirchen R, Longerich T, Costa IG, Anstee QM, Trautwein C, Tacke F. Therapeutic inhibition of inflammatory monocyte recruitment reduces steatohepatitis and liver fibrosis. Hepatology 2018;67(4):1270-83.

[16] Berres ML, Koenen RR, Rueland A, Zaldivar MM, Heinrichs D, Sahin H, Schmitz P, Streetz KL, Berg T, Gassler N, Weiskirchen R, Proudfoot A, Weber C, Trautwein C, Wasmuth HE. Antagonism of the chemokine Ccl5 ameliorates experimental liver fibrosis in mice. J Clin Invest 2010;120(11):4129-40.

[17] Miura K, Yang L, van Rooijen N, Ohnishi H, Seki E. Hepatic recruitment of macrophages promotes nonalcoholic steatohepatitis through CCR2. Am J Physiol Gastrointest Liver Physiol 2012;302(11):G131021.

[18] Schwabe RF, Tabas I, Pajvani UB. Mechanisms of Fibrosis Development in Nonalcoholic Steatohepatitis. Gastroenterology 2020;158(7):1913-28.

[19] Karsdal MA, Nielsen SH, Leeming DJ, Langholm LL, Nielsen MJ, Manon-Jensen T, Siebuhr A, Gudmann NS, Ronnow S, Sand JM, Daniels SJ, Mortensen JH, Schuppan D. The good and the bad collagens of fibrosis - Their role in signaling and organ function. Adv Drug Deliv Rev 2017;121:43-56.

[20] Schuppan D, Surabattula R, Wang XY. Determinants of fibrosis progression and regression in NASH. J Hepatol 2018;68(2):238-50.

[21] Rockey DC, Bell PD, Hill JA. Fibrosis-a common pathway to organ injury and failure. N Engl J Med 2015;372(12):1138-49.

[22] van Niel G, D'Angelo G, Raposo G. Shedding light on the cell biology of extracellular vesicles. Nat Rev Mol Cell Biol 2018;19(4):213-28.

[23] Mathieu M, Martin-Jaular L, Lavieu G, Thery C. Specificities of secretion and uptake of exosomes and other extracellular vesicles for cell-to-cell communication. Nat Cell Biol 2019;21(1):9-17.

[24] Saha S, Aranda E, Hayakawa Y, Bhanja P, Atay S, Brodin NP, Li J, Asfaha S, Liu L, Tailor Y, Zhang J, Godwin AK, Tome WA, Wang TC, Guha C, Pollard JW. Macrophage-derived extracellular vesicle-packaged Loading [MathJax]/jax/output/CommonHTML/jax.js 
WNTs rescue intestinal stem cells and enhance survival after radiation injury. Nat Commun 2016;7:13096.

[25] Vajen T, Benedikter BJ, Heinzmann ACA, Vasina EM, Henskens Y, Parsons M, Maguire PB, Stassen FR, Heemskerk JWM, Schurgers LJ, Koenen RR. Platelet extracellular vesicles induce a pro-inflammatory smooth muscle cell phenotype. J Extracell Vesicles 2017;6(1):1322454.

[26] Hirsova P, Ibrahim SH, Krishnan A, Verma VK, Bronk SF, Werneburg NW, Charlton MR, Shah VH, Malhi H, Gores GJ. Lipid-Induced Signaling Causes Release of Inflammatory Extracellular Vesicles From Hepatocytes. Gastroenterology 2016;150(4):956-67.

[27] Shibata N, Watanabe T, Okitsu T, Sakaguchi M, Takesue M, Kunieda T, Omoto K, Yamamoto S, Tanaka N, Kobayashi N. Establishment of an immortalized human hepatic stellate cell line to develop antifibrotic therapies. Cell Transplant 2003;12(5):499-507.

[28] Witwer KW, Buzas El, Bemis LT, Bora A, Lasser C, Lotvall J, Nolte-'t Hoen EN, Piper MG, Sivaraman S, Skog J, Thery C, Wauben MH, Hochberg F. Standardization of sample collection, isolation and analysis methods in extracellular vesicle research. J Extracell Vesicles 2013;2.

[29] Heinrichs D, Berres ML, Coeuru M, Knauel M, Nellen A, Fischer P, Philippeit C, Bucala R, Trautwein C, Wasmuth HE, Bernhagen J. Protective role of macrophage migration inhibitory factor in nonalcoholic steatohepatitis. FASEB J 2014;28(12):5136-47.

[30] McCloy RA, Rogers S, Caldon CE, Lorca T, Castro A, Burgess A. Partial inhibition of Cdk1 in G 2 phase overrides the SAC and decouples mitotic events. Cell Cycle 2014;13(9):1400-12.

[31] Guo Q, Furuta K, Lucien F, Gutierrez Sanchez LH, Hirsova P, Krishnan A, Kabashima A, Pavelko KD, Madden B, Alhuwaish H, Gao Y, Revzin A, Ibrahim SH. Integrin beta1-enriched extracellular vesicles mediate monocyte adhesion and promote liver inflammation in murine NASH. J Hepatol 2019;71(6):1193-205.

[32] Kakazu E, Mauer AS, Yin M, Malhi H. Hepatocytes release ceramide-enriched pro-inflammatory extracellular vesicles in an IRE1 alpha-dependent manner. J Lipid Res 2016;57(2):233-45.

[33] Ibrahim SH, Hirsova P, Tomita K, Bronk SF, Werneburg NW, Harrison SA, Goodfellow VS, Malhi H, Gores GJ. Mixed lineage kinase 3 mediates release of C-X-C motif ligand 10-bearing chemotactic extracellular vesicles from lipotoxic hepatocytes. Hepatology 2016;63(3):731-44.

[34] Takahashi Y, Fukusato T. Histopathology of nonalcoholic fatty liver disease/nonalcoholic steatohepatitis. World J Gastroenterol 2014;20(42):15539-48.

[35] Lepreux S, Desmouliere A. Human liver myofibroblasts during development and diseases with a focus on portal (myo)fibroblasts. Front Physiol 2015;6:173.

Loading [MathJax]/jax/output/CommonHTML/jax.js

Page 14/19 
[36] Liao CY, Song MJ, Gao Y, Mauer AS, Revzin A, Malhi H. Hepatocyte-Derived Lipotoxic Extracellular Vesicle Sphingosine 1-Phosphate Induces Macrophage Chemotaxis. Front Immunol 2018;9:2980.

[37] Momen-Heravi F, Bala S, Kodys K, Szabo G. Exosomes derived from alcohol-treated hepatocytes horizontally transfer liver specific miRNA-122 and sensitize monocytes to LPS. Sci Rep 2015;5:9991.

[38] Xiong X, Kuang H, Ansari S, Liu T, Gong J, Wang S, Zhao XY, Ji Y, Li C, Guo L, Zhou L, Chen Z, LeonMimila P, Chung MT, Kurabayashi K, Opp J, Campos-Perez F, Villamil-Ramirez H, Canizales-Quinteros S, Lyons R, Lumeng CN, Zhou B, Qi L, Huertas-Vazquez A, Lusis AJ, Xu XZS, Li S, Yu Y, Li JZ, Lin JD. Landscape of Intercellular Crosstalk in Healthy and NASH Liver Revealed by Single-Cell Secretome Gene Analysis. Mol Cell 2019;75(3):644-60 e5.

[39] Ramachandran P, Dobie R, Wilson-Kanamori JR, Dora EF, Henderson BEP, Luu NT, Portman JR, Matchett KP, Brice M, Marwick JA, Taylor RS, Efremova M, Vento-Tormo R, Carragher NO, Kendall TJ, Fallowfield JA, Harrison EM, Mole DJ, Wigmore SJ, Newsome PN, Weston CJ, Iredale JP, Tacke F, Pollard JW, Ponting CP, Marioni JC, Teichmann SA, Henderson NC. Resolving the fibrotic niche of human liver cirrhosis at single-cell level. Nature 2019;575(7783):512-8.

\section{Figures}

A

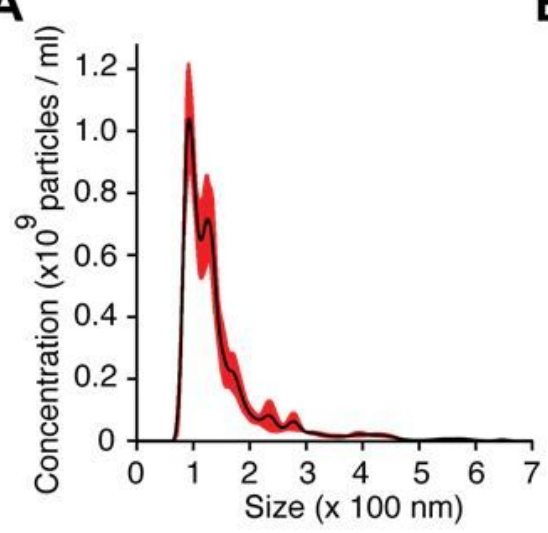

D

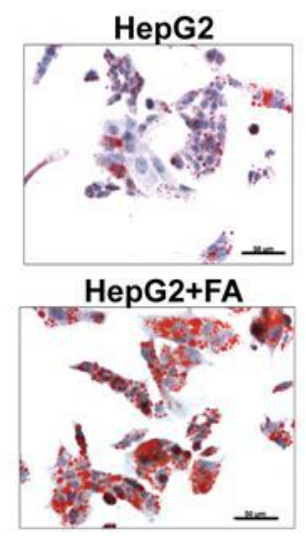

B

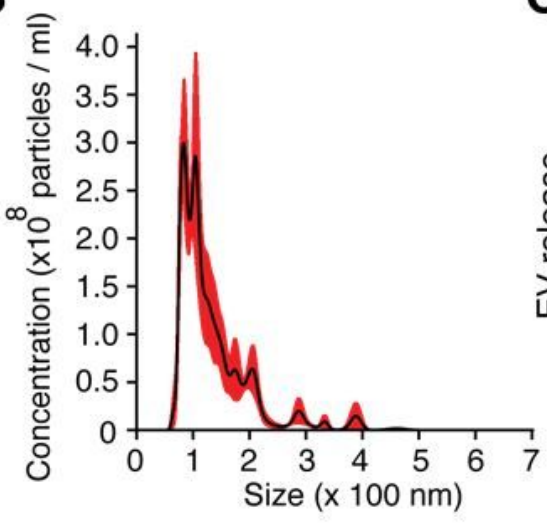

$\mathbf{F}$

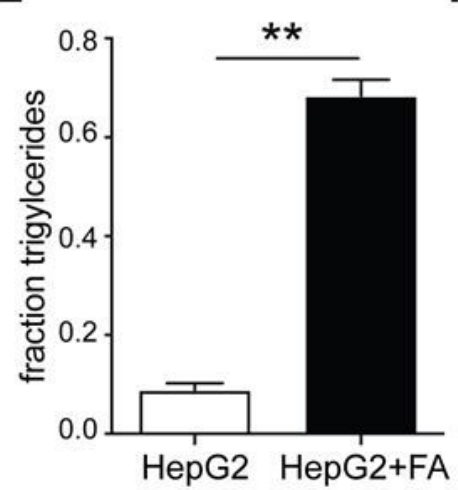

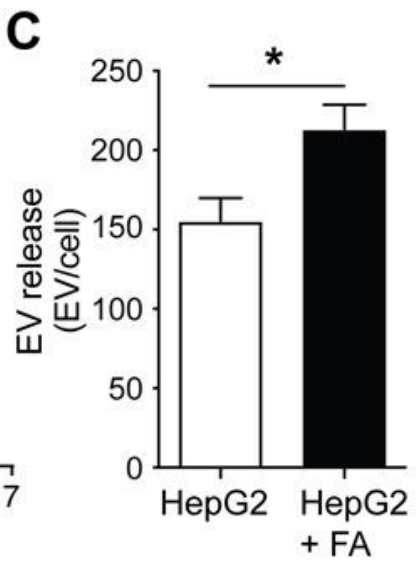

G

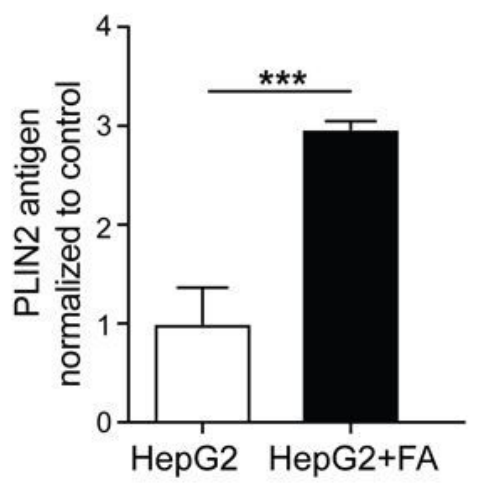

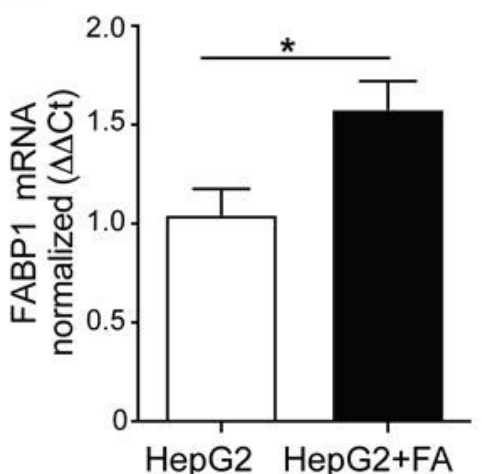


Figure 1

Treatment with fatty acids induces steatosis in HepG2 cells NTA analysis of EV in media of HepG2 cells collected under (A) resting conditions or (B) after treatment with linoleic-oleic-acid for 24 hours. (C) Expression of EV release as number of EV per cell. (D) Representative oil-red-o staining after treatment with linoleic-oleic-acid for 24 hours. Scale bar: $50 \mu \mathrm{m}$. Fraction of triglycerides in cell lysates (E), antigen levels of PLIN2 (F) and mRNA expression levels of FABP1 (G) after treatment with linoleic-oleic-acid for 24 hours. ${ }^{*} P<0.05,{ }^{*} P<0.01,{ }^{* * *} P<0.001$ with 2-tailed t-test, mean $\pm S E M(n=3)$.
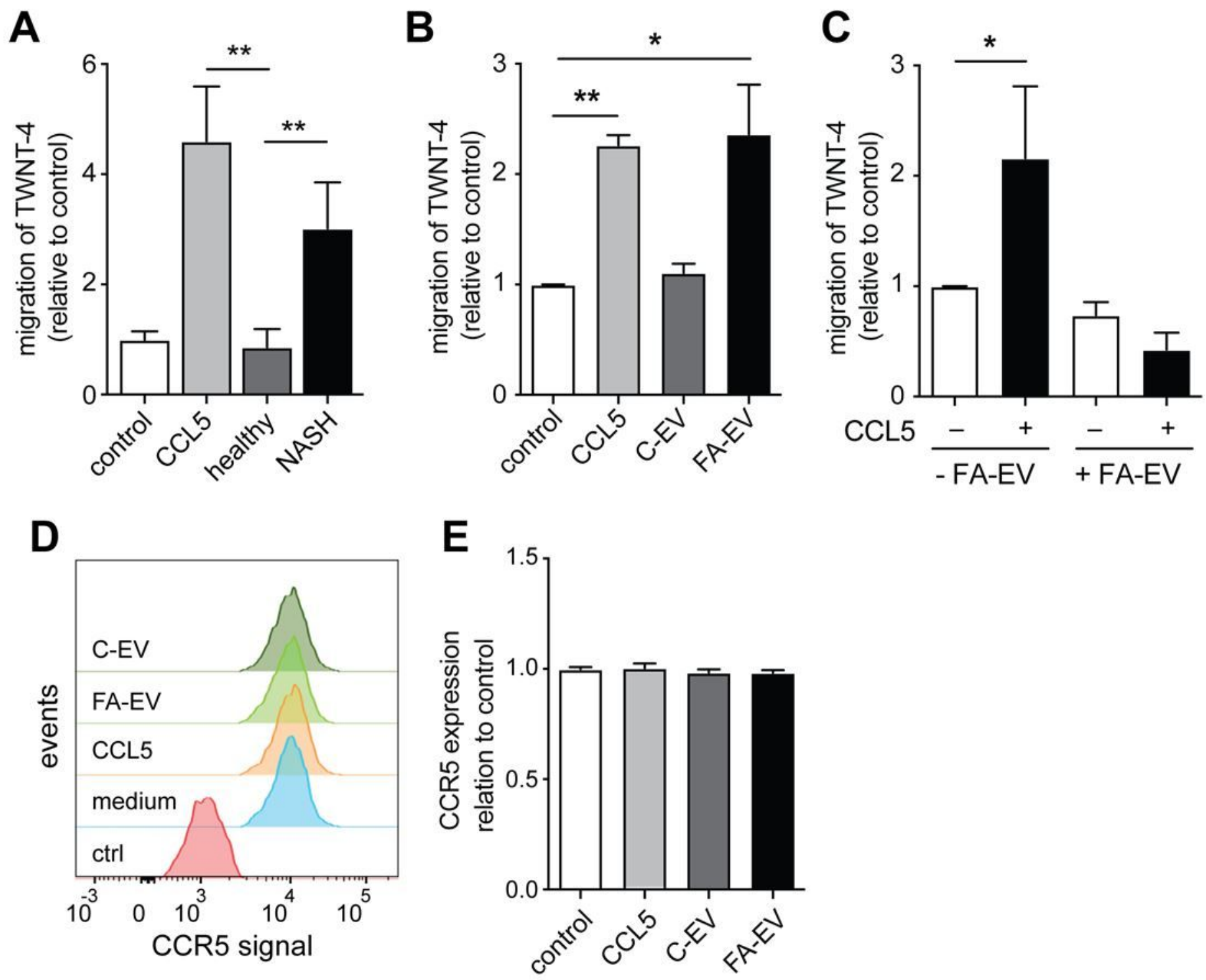

Figure 2

Migration of TWNT4 cells towards patient sera and EV released from HepG2 cells. Chemotaxis of TWNT4 cells towards CCL5 or (A) sera from individuals without or with NASH, or (B) EV harvested from HepG2 under resting conditions (C-EV) or after treatment with linoleic-oleic-acid for 24 hours (FA-EV). Five view fields were counted ner filter and normalized to control. (C) Chemotaxis of TWNT4 cells towards CCL5 Loading [MathJax]/jax/output/CommonHTML/jax.js 
without or with pre-treatment with FA-EV for 24 hours. Representative histograms (D) and quantitation (E) of CCR5 expression of TWNT4 cells after pretreatment with CCL5, C-EV or FA-EV. ${ }^{*} P<0.05,{ }^{\star \star} P<0.01$ with ANOVA and Bonferroni test, mean \pm SEM $(n=3)$.
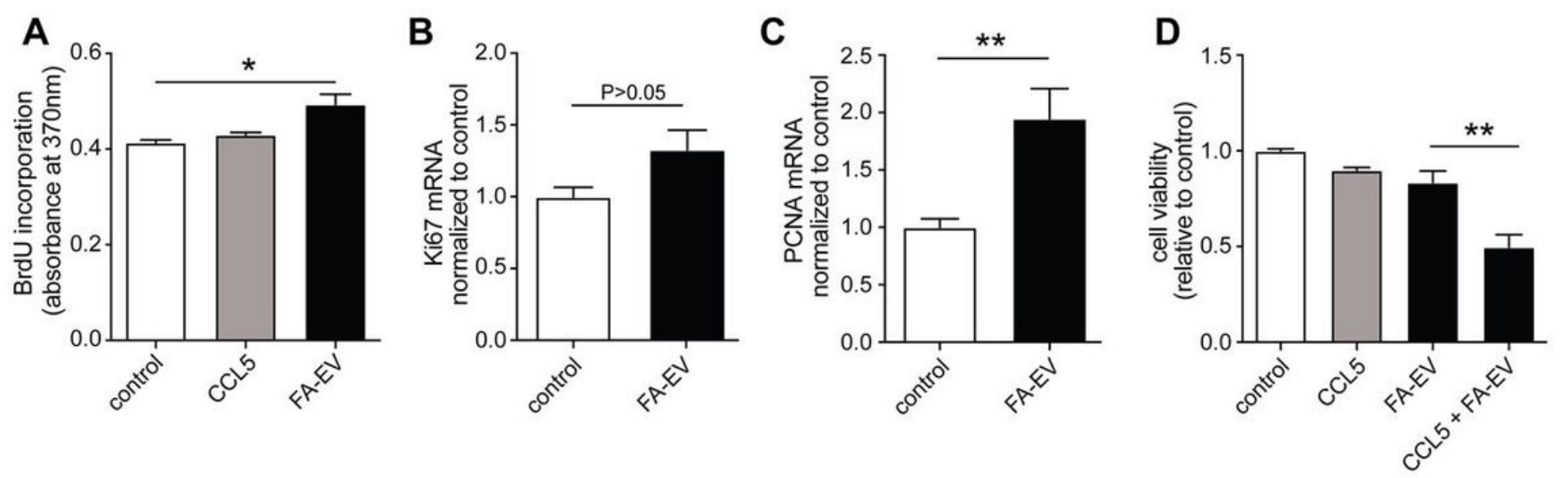

Figure 3

Proliferation and cell viability of TWNT4 cells after EV treatment. (A) Proliferation of TWNT4 cells measured by BrdU-incorporation after treatment with CCL5 or FA-EV. (B) Expression of the proliferation markers Ki67 (B) and PCNA (C) after treatment of TWNT4 with FA-EV. (D) Viability of TWNT4 cells after treatment with CCL5, FA-EV or a combination of CCL5 and FA-EV. ${ }^{*} \mathrm{P}<0.05,{ }^{*} \mathrm{P}<0.01$ with ANOVA and Bonferroni test or 2-tailed t-test, mean \pm SEM ( $n=3-4)$.
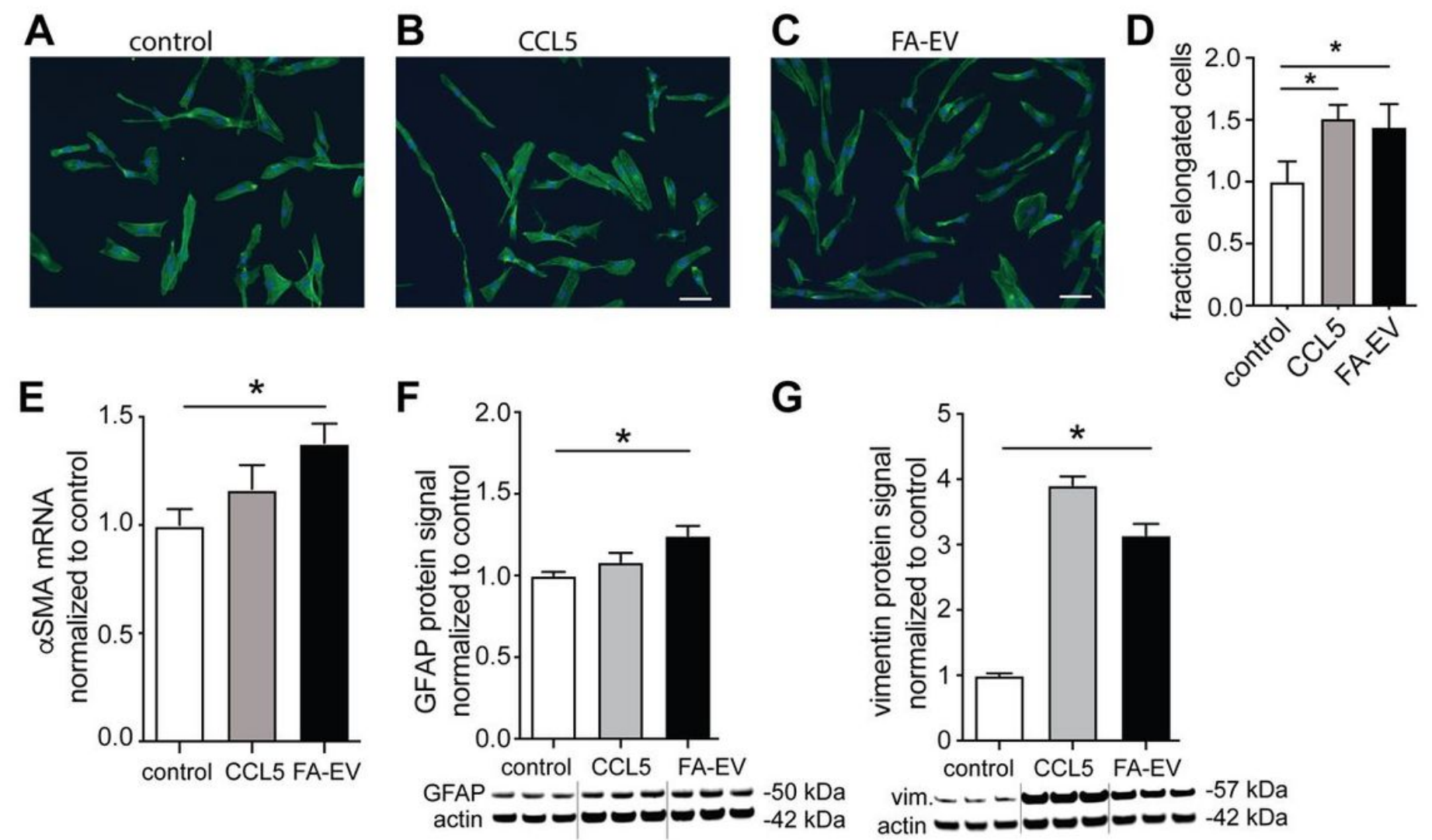


\section{Figure 4}

Morphology and collagen production of FA-EV-treated TWNT4 cells. Representative phalloidin staining

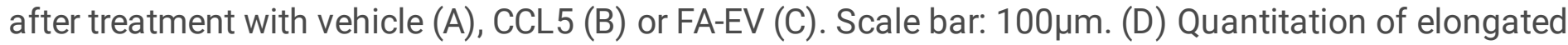

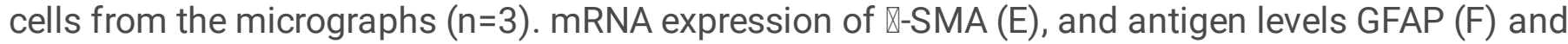
vimentin $(\mathrm{G})$ after treatment with vehicle, CCL5 or FA-EV. ${ }^{*}<0.05$ with ANOVA and Bonferroni test, mean \pm SEM $(n=3-5)$.
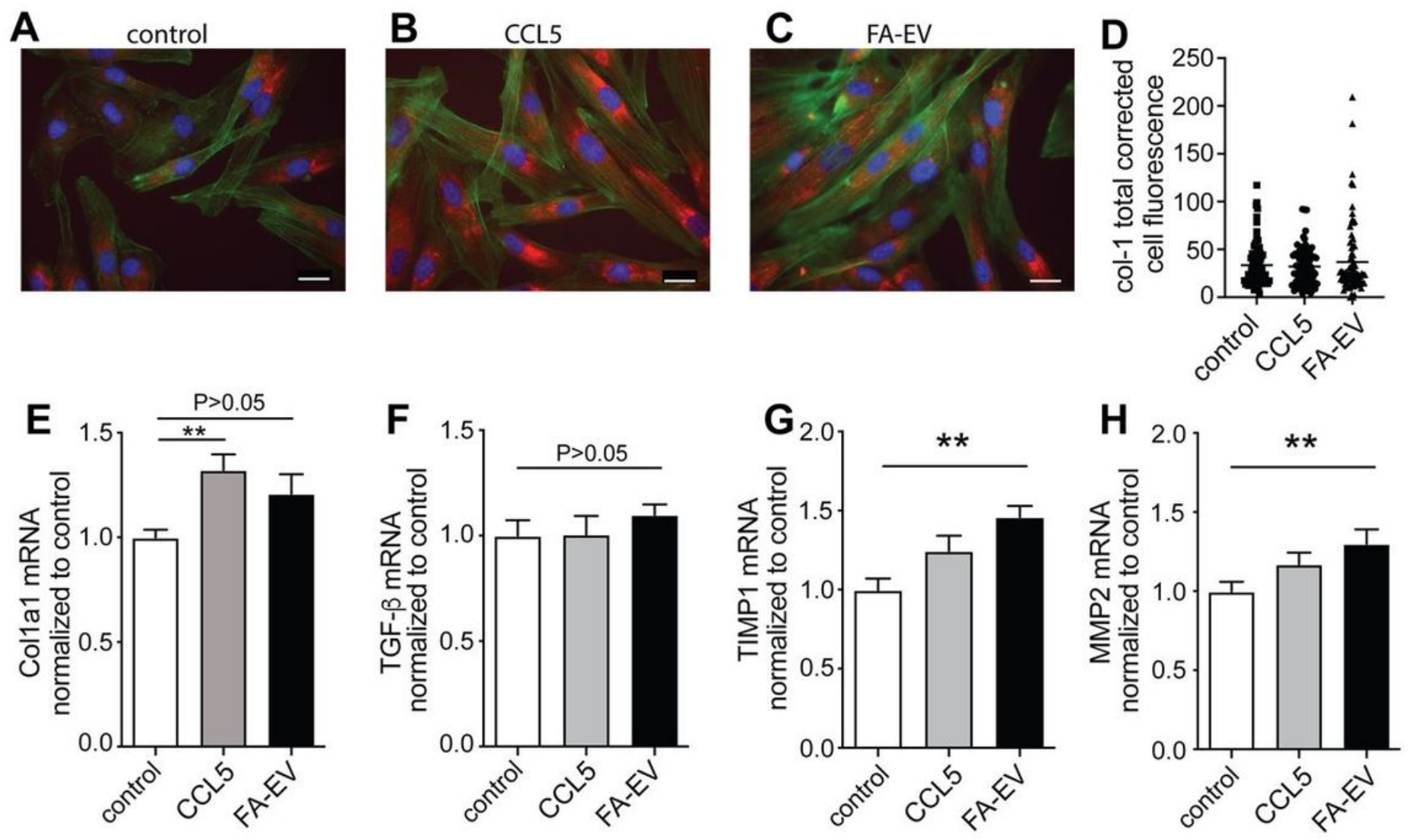

\section{Figure 5}

Expression of fibrotic markers in FA-EV-treated TWNT4 cells. Representative phalloidin staining and collagen staining after treatment with vehicle (A), CCL5 (B) or FA-EV (C), scale bar: $20 \mu \mathrm{m}$. (D)

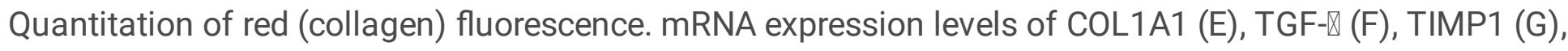
MMP2 $(\mathrm{H})$, after treatment with vehicle, CCL5 or FA-EV. ${ }^{*} \mathrm{P}<0.01$ with ANOVA and Bonferroni test, mean $\pm S E(n=3-5)$. 

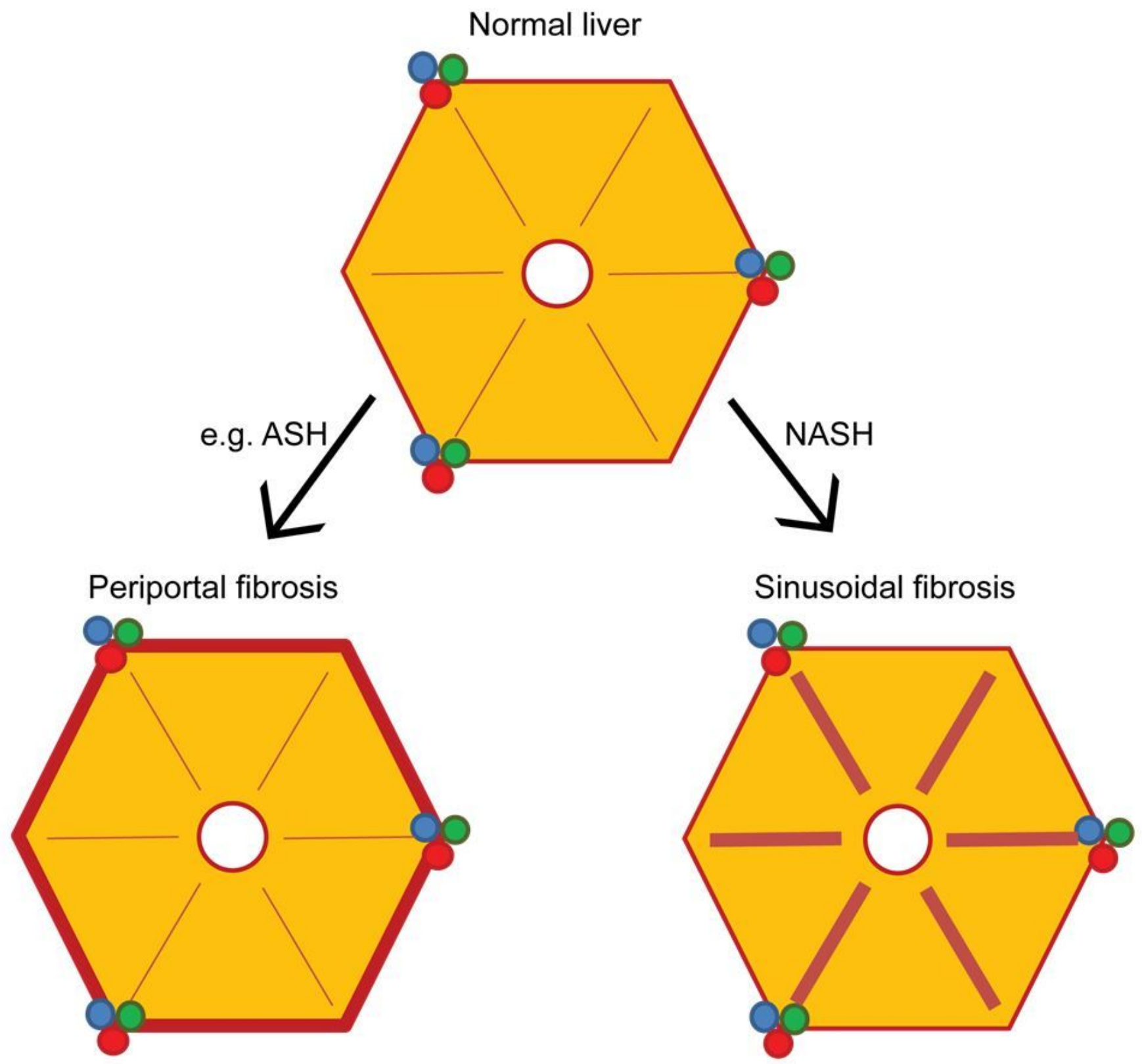

\section{Figure 6}

Schematic representation of the liver fibrosis process. Schematic representation of the typical patterns of pathologic matrix deposition during e.g. alcoholic steatohepatitis (ASH), viral hepatitis and primary sclerosing cholangitis (left) versus non-alcoholic steatohepatitis (NASH, right) [34]. 